Dhaka Univ. J. Biol. Sci. 29(1): 45-52, 2020 (January)

\title{
EFFECTS OF CADMIUM ON THE ANATOMICAL STRUCTURES OF VEGETATIVE ORGANS OF CHICKPEA (CICER ARIENTINUM L.)
}

\author{
Saima Jahan Liza, Kishwar Jahan Shethi* and Parveen Rashid \\ Department of Botany, University of Dhaka, Dhaka-1000, Bangladesh \\ Key words: Chickpea, Cadmium, Anatomy, Vascular bundle
}

\begin{abstract}
The effects of cadmium on the anatomical structures of different vegetative parts, namely root, stem and leaf of chickpea, Cicer arientinum L. was studied. Four different concentrations of $\mathrm{CdCl}_{2}$ e.g. 250, 500, 750 and $1000 \mu \mathrm{M}$ were considered as treatments alongside non treated samples (control). In case of root anatomy decrease of root diameter, root cortex area, thick walled endodermal layer and reduced number of metaxylem vessels were observed compared to control. Similarly, stem diameter, cortical area, size and number of xylem vessels were decreased in $\mathrm{Cd}$ treated stem. However, large and increased number of trichomes had been found in $\mathrm{Cd}$ treated stem samples with deposition of phenolic compounds in vessels with increasing concentration of $\mathrm{Cd}$. Considerable less toxic effects were observed in leaf anatomy except decrease in leaf thickness, reduced vascular area and closure of stomata in comparison to control sample. All such plant anatomical alterations indicated adverse effects as well as tolerance of chickpea up to certain concentrations of heavy metal to cope up with the changing environment.
\end{abstract}

\section{Introduction}

Of all non-essential heavy metals, cadmium $(\mathrm{Cd})$ is perhaps the one that has attracted the most attention in soil science and plant nutrition due to its potential toxicity to humans, and also its relative mobility in the soil-plant system ${ }^{(1)}$. There are two types of causal relationships existing between the high concentration of heavy metals in the soil and the expression of toxicity symptoms. On the one hand, heavy metals compete with essential mineral nutrients for uptake thereby disturbing the mineral nutrition of plants ${ }^{(2)}$ and on the other hand, after uptake by the plant it accumulates in plant tissue and cell compartments and hampers the general metabolism of the plant $t^{(3-5)}$. When excessive amount of $\mathrm{Cd}$ is present in soil and water a range of plant responses occur, including leaf chlorosis, stunted growth, reduced photosynthesis, reduced plant fresh and dry mass and stomatal conductance, and even death. In Bangladesh contamination rates of arsenic, lead and mercury are alarming, while levels of cadmium and aluminum are of serious

*Author for correspondence: <kishwar.botany@du.ac.bd> 
concern. An alarming 94 per cent of poor and 78 per cent of non-poor households were found to be exposed to cadmium in excess of provisional tolerable weekly intake ${ }^{(6)}$.

Morphology, anatomy and physiology of plants are likely to provide clues towards their adaptation to various growing conditions ${ }^{(7)}$. Several studies are carried out to date to investigate the impact of heavy metals on one or a few anatomical parameters of the different plant species ${ }^{(8-10)}$. No work concerning the effects of $\mathrm{Cd}$ on the anatomical structures of economically important crops from Bangladesh have been reported yet. During the present work chickpea was taken as an experimental material since it has been postulated that higher plants are more sensitive to $\mathrm{Cd}$ stress ${ }^{(11)}$. At the same time chickpea is an economically important pulse for Bangladesh considering its nutritive value, production and consumption.

Study on the anatomical structures of chickpea due to effect of $\mathrm{Cd}$ will ameliorate the understanding of the plant cellular response towards $\mathrm{Cd}$ heavy metal toxicity and also any mechanism that lies beyond plant metal tolerance and homeostasis. Therefore, the present investigation was initiated to study the changes in anatomical structures in chickpea due to $\mathrm{Cd}$.

\section{Materials and Methods}

The seeds of chickpea (Cicer arietinum L.) var. BARI Chola 5 were collected from BARI and kept in airtight plastic packets at $4^{\circ} \mathrm{C}$. Plants were grown in sand culture. Modified half-strength Hoagland solution ${ }^{(12)}$ was used as nutrient solution. The seeds were surface sterilized with sodium hypochlorite $(4-7 \%)$ to avoid any fungal infection. Modified half strength Hoagland solution was applied to control plants and 250, 500, 750 and $1000 \mu \mathrm{M} \mathrm{CdCl}_{2}$ solution were applied to treat plants at alternate day up to 14 days. For root and stem anatomy middle part of the root and $2 \mathrm{~cm}$ above from the base of the stem was taken, respectively. For leaf anatomy trichome and stomata present on ventral side of the third leaf of the 14 days old plant were studied. The sections were stained with safranin and mounted in $20 \%$ glycerin. Transverse sections of root, stem and leaf were studied under a compound light microscope (Nikon ECLIPSE E200) at different magnification. Micrographs of the sections were taken using a digital camera (Nikon UFY-11A, Japan) attached with microscope. The plants were grown and maintained in net house condition and all the experiments were carried out in the Plant Physiology, Biochemistry and Plant Nutrition laboratory, Department of Botany, University of Dhaka.

\section{Results and Discussion}

As compared to control root diameter decreased in $\mathrm{Cd}$ treated plants. Both in control and $\mathrm{Cd}$ treated roots, epidermis was single layered with thin walled parenchymatous

cell. Cortex composed of thin walled parenchymatous cells just beneath the epidermis. In 
control plant root, 12 - 14 layers of cortical cell present whereas in Cd treated plant root, it was 8 - 10 (Figs 1a-e). Usually roots were characterized by the presence of single layered endodermis. Cells were barrel shaped in both control and Cd treated roots. In Cd treated roots endodermal cells were smaller and thick walled as compared to control plant root (Fig. 1f). Pericycle was single layered just beneath the endodermis both in control and treated plant (Figs 1f-j). Remarkable structural changes induced in root tissue by exposure of the plant to $\mathrm{Cd}$ occurred in vascular system. In $\mathrm{Cd}$ treated root, diameter of metaxylem vessels decreased. Smaller metaxylem vessels were also found in $\mathrm{Cd}$ treated root (Figs 1g-j). Parenchymatous pith was smaller in Cd treated plant roots (Figs $1 \mathrm{~b}-\mathrm{e})$. Similar negative effects were observed in root anatomical traits in maize seedlings by combined effect of $\mathrm{Cu}$ and $\mathrm{Cd}^{(13)}$ and vascular elements of fenugreek and chickpea, ${ }^{(14,15)}$ respectively.

Diameter of the stem decreased in $\mathrm{Cd}$ treated stem. This smaller diameter was related with the reduction in cell size and also with reduction in size of the vascular elements. Stem is circular in outline in control plant whereas it is slightly wavy in $\mathrm{Cd}$ treated stem (Figs 2a-e). In the stem of control and $\mathrm{Cd}$ treated samples epidermis was monoseriate where cells were radially elongated. However, in $\mathrm{Cd}$ treated stem epidermal cells were thicker. Epidermal cell grew out in the form trichome. Multicellular glandular trichomes were found both in control and $\mathrm{Cd}$ treated stem. Trichomes were numerous in number in Cd treated stem as compared to control stem (Figs 2c-e). Increased number of trichomes refers to defense mechanism in response to stress. Compared to the control (Fig. 2a), trichomes were higher in length and trichome head was damaged in higher $(1000 \mu \mathrm{M})$ concentrations of Cd (Fig. 3b). Such damage indicated toxic effect was increasing with increasing concentration of $\mathrm{Cd}$. The cortical cells of the $\mathrm{Cd}$ treated stem occupied smaller area than that of the control stem in chickpea (Figs 2a-e). The number of cortical layer was 10 - 12 whereas it was 14 - 16 in control plant. However, reverse result had been reported in Trigonella foenum-graecum when $\mathrm{Cd}$ and $\mathrm{Pb}$ were applied(14). Vascular bundles were radially arranged. Secondary growth was observed in the stem of both control and $\mathrm{Cd}$ treated stem. In $\mathrm{Cd}$ treated stem cambium ring was thin. Size and number of xylem vessel was reduced in $\mathrm{Cd}$ treated stem (Figs 2g-j). Groups of sclerenchyma were superimposed upon the phloem. Number of sclerenchymatous patches increased in Cd treated stem (Figs 2g-j). Subdued appearance of xylem and phloem elements of stem in comparison to control samples were also reported in fenugreek and chickpea, respectively ${ }^{(14,15)}$. Phenolic compounds were found in vessel of higher concentration of $\mathrm{Cd}$ treated stem Figs $2 \mathrm{i}-\mathrm{j}$ ).

Much of the Cd taken up by plants is retained in the roots, but a portion is translocated to the aerial portions of the plant in general. Therefore, minimum changes in the anatomical characteristics of leaves had been observed. Similar observation of having anatomical changes only in roots and stems in B.juncea plants exposed to higher 

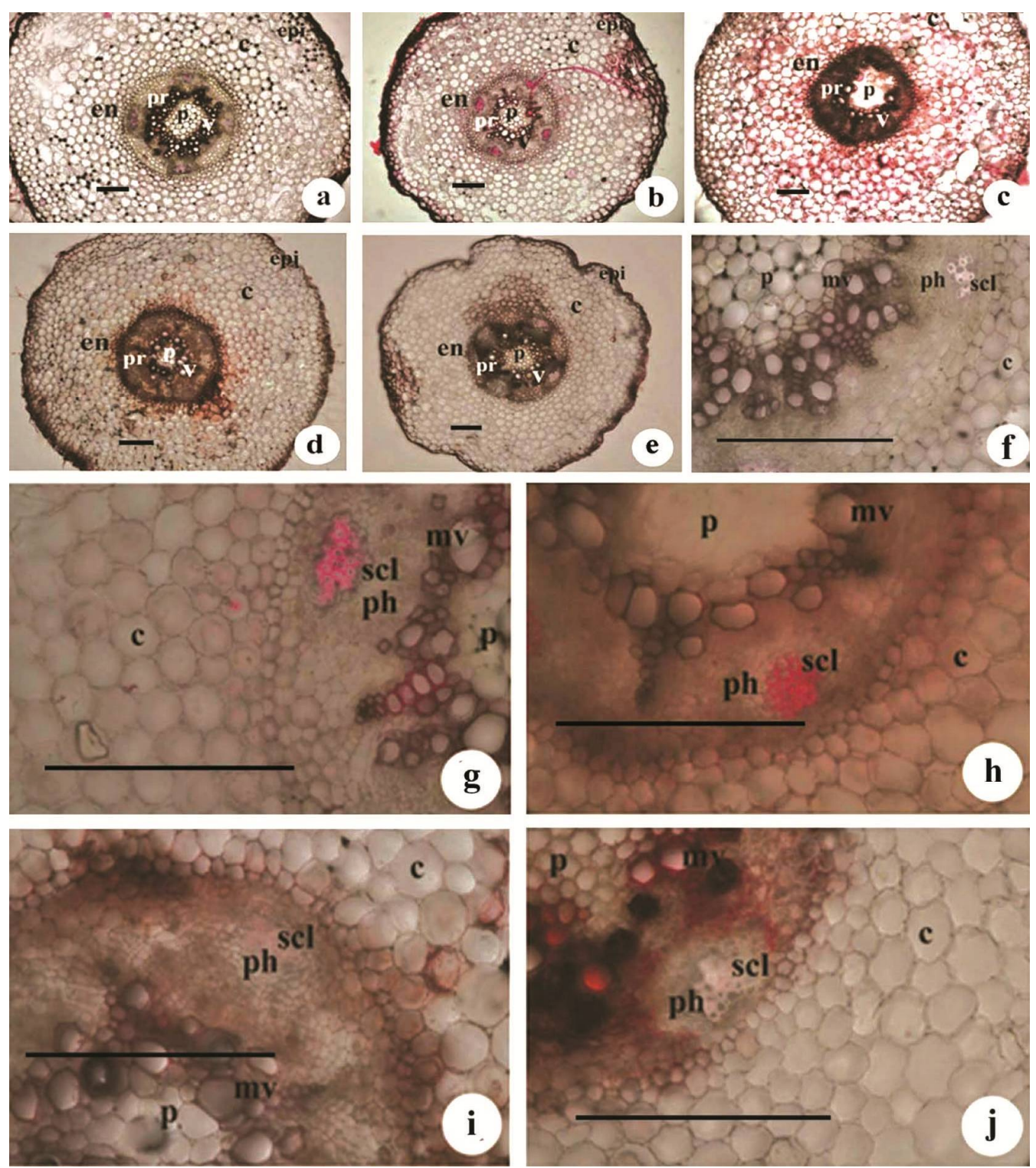

Fig. 1. Transverse section of the root of chickpea under 40X magnification. a - control, b- $250 \mu \mathrm{M}$, c $-500 \mu \mathrm{M}, \mathrm{d}-750 \mu \mathrm{M}, \mathrm{e}-1000 \mu \mathrm{M}$ Cd treated plant showing epidermis (epi), cortex (c), endodermis (en), vascular tissue (v), pith (p) and pericycle (pr). Transverse section of the root of chickpea under 400X magnification f - control, g - $250 \mu \mathrm{M}, \mathrm{h}-500 \mu \mathrm{M}, \mathrm{i}-750 \mu \mathrm{M}, \mathrm{j}-1000 \mu \mathrm{M}$ $\mathrm{Cd}$ treated plant showing cortex (c), endodermis (en), meta vessel (mv), pith (p) and schlerenchyma (scl). Bar $=50 \mu \mathrm{m}$. 

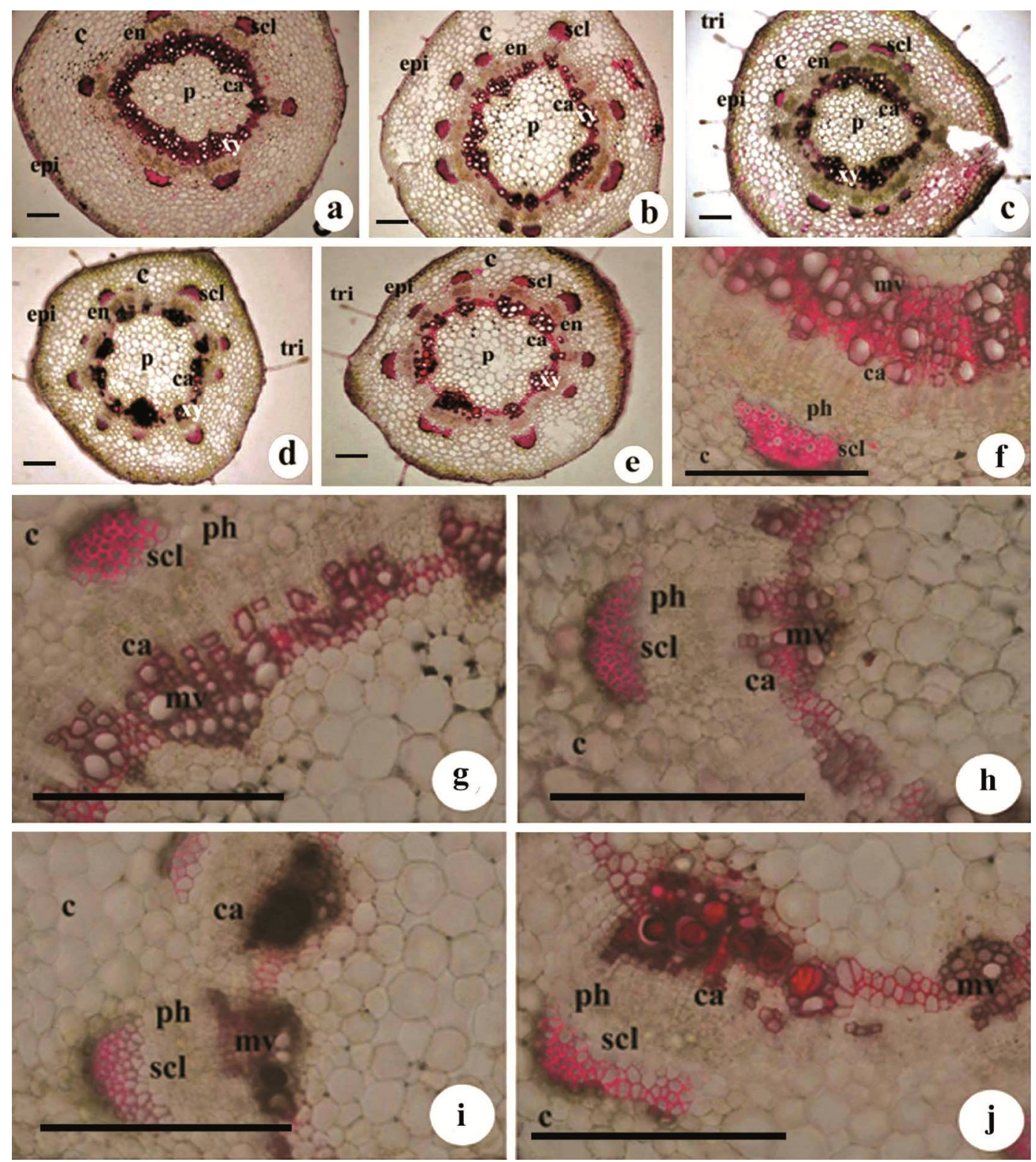

Fig. 2. Transverse section of the stem of chickpea under 40X magnification. a - control, b - $250 \mu \mathrm{M}$, c - $500 \mu \mathrm{M}, \mathrm{d}-750 \mu \mathrm{M}, \mathrm{e}-1000 \mu \mathrm{M}$ Cd treated plant showing epidermis (epi), cortex (c), endodermis (en), xylem (xy), pith (p), cambium (ca), schlerenchyma (scl) and pericycle (pr). Transverse section of the stem of chickpea under 400X magnification f. control, g - $250 \mu \mathrm{M}$, h - $500 \mu \mathrm{M}, \mathrm{i}-750 \mu \mathrm{M}, \mathrm{j}-1000 \mu \mathrm{M}$ Cd treated plant showing cortex (c), metavessel (mv), pith (p), cambium (ca), schlerenchyma (scl) and phloem (ph). Bar $=50 \mu \mathrm{m}$. 

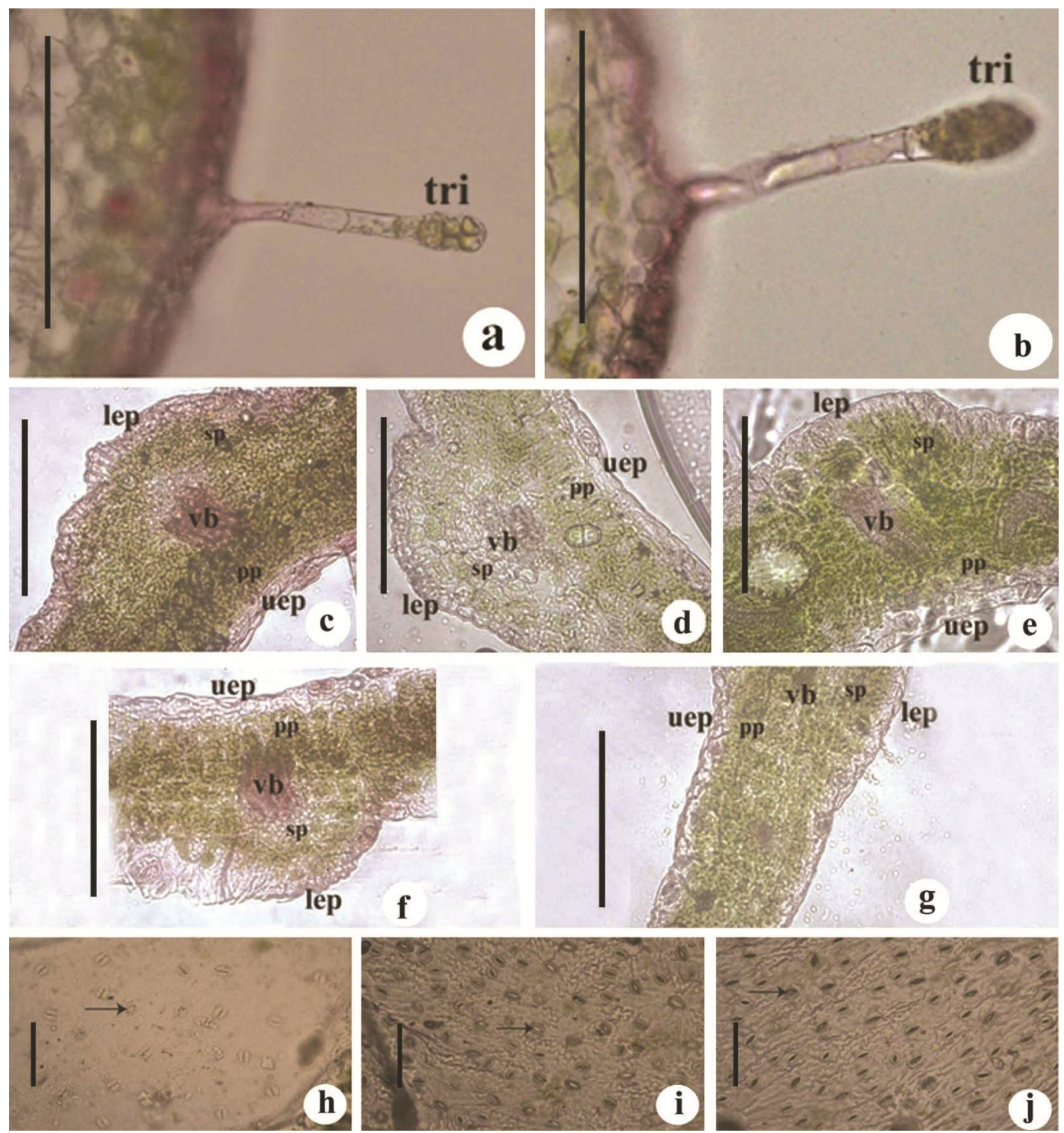

Fig. 3. Transverse section of the stem of chickpea under 1000X magnification. a - control, b - $1000 \mu \mathrm{M} \mathrm{Cd}$ treated plant showing trichome (tri). Transverse section of the leaf of chickpea under 400X magnification. c - control, d - $250 \mu \mathrm{M}, \mathrm{e}-500 \mu \mathrm{M}, \mathrm{f}-750 \mu \mathrm{M}, \mathrm{g}-1000 \mu \mathrm{M}$ Cd treated plant showing upper epidermis (uep), lower epidermis(lep), vascular bundle(vb), palisade parenchyma (pp) and spongy parenchyma (sp). Peel of the leaf of chickpea h - control, i - $250 \mu \mathrm{M}$ and $\mathrm{j}-1000 \mu \mathrm{M} \mathrm{Cd}$ treatment showing open and closed stomata and guard cell under 100X magnification. Bar $=50 \mu \mathrm{m}$.

concentration of $\mathrm{Cd}$ had been reported(16). Breadth of the midrib as well as laminar portion decreased in $\mathrm{Cd}$ treated plants (Figs 3d-g) compared to control Fig. 3c). No significant changes had been found in epidermis and mesophyll tissue of both $\mathrm{Cd}$ treated 
and control chickpea leaves. Collateral vascular bundle was situated in the center of the midrib and surrounded by parenchymatous bundle sheath. Vascular area in $\mathrm{Cd}$ treated leaf became smaller as compared to control leaf (Figs 3c-g). Combined effect of $\mathrm{Cu}$ and $\mathrm{Cd}$ caused decrease in leaf structural traits as thickness of midrib, upper epidermis, parenchyma and vascular bundle in maize seedlings ${ }^{(13)}$. Cd-induced xerophyte anatomic features of leaves (i.e. thick lamina, upper epidermis, palisade mesophyll, high palisade to spongy thickness ratio, as well as abundant and small stomata) had been observed ${ }^{(17)}$ which was not in congruent to present findings.

In the leaf of 14 days old $\mathrm{Cd}$ treated plant, stomata were open in control whereas $\mathrm{Cd}$ treatment caused closure of stomata of chickpea plants (Figs 3h-j). Closure of stomata might be due to increase in abscisic acid level and decrease the rate of photosynthesis by Cd.

Chickpea plants showed gradual degeneration of different anatomical features in the root, stem and leaf transverse sections under Cd stress. Subnormal appearance of xylem and phloem elements was significant across all studied organs, namely root, stem and leaf in comparison to control that indicated toxic effect of $\mathrm{Cd}$ leading towards subdued conduction of water and photosynthates. Moreover, changes on anatomical traits were somewhat dependent on $\mathrm{Cd}$ concentration as the changes were more pronounced with increasing Cd concentration. Even the effect of $\mathrm{Cd}$ in a tolerant species Schinus molle was concentration dependent, and at low $\mathrm{Cd}$ concentrations, these plants could cope with the toxicity by adjusting leaf structure and function ${ }^{(18)}$. Thus the present investigation revealed that $\mathrm{Cd}$ had detrimental effects on the anatomical structures of chickpea with increasing concentration of $\mathrm{Cd}$ although the plant struggled to minimize such effects by modifying the cellular structures to some extent. Further studies of anatomical structures in relation to growth and biochemical changes will ameliorate authors' understanding of the plant cellular responses towards Cd toxicity in crop plants.

\section{References}

1. Tran TA, Paunova S, Nedeva D and Popova L 2011. Nitric oxide alleviates cadmium toxicity on photosynthesis in pea plants. C. R. Acad. Bulg. Sci. 64: 1137-1142.

2. Clarkson DT and Luttge U 1989. Mineral nutrition: Divalent cations, transport and compartmentalization. Prog. Bot. 51: 93-112.

3. Thurman DA and Collins JCL 1983. Metal tolerance mechanism in higher plants review. In: Proceedings of International Conference on Heavy Metals in the Environment, pp. 298300. CEP Consultan's Edimburg, Heidelberg.

4. Taylor K, Albrigo LG and Chase CD 1988. Zinc complexation in the phloem of blight affected citrus. J. Am. Soc. Hortic. Sci. 113: 407-411.

5. Turner MA 1997. Effect of cadmium treatment on cadmium and zinc uptake by selected vegetable species. J. Environ. Qual. 2: 118-119. 
6. FPMU (Food Planning and Monitoring Unit), Food Security Policy Brief, 2014 (September). Ministry of Food of the Government of Bangladesh, with the assistance of the National Food Policy Capacity Strengthening Programme (NFPCSP) and the Food and Agriculture Organization of the United Nations (FAO).

7. Chandler JN and Bartels D 2008. Drought : Avoidance and adaptation. In: SW Trimble, BA Stewart and TA Howel eds, Encyclopedia of Water Science. Taylor and Francis Group, London. pp. 224.

8. Khudsar T, Muzzafar and M Iqbal 2001. Cadmium-induced changes in leaf epidermis, photosynthetic rate and pigment concentrations in Cajanus cajan. Biol. Pl. 44: 59-64.

9. Panou-Filotheou $\mathrm{H}$ and Bosabalidis AM 2004. Root structural aspects associated with copper toxicity in oregano (Origanum vulgare subsp. hirtum). Pl. Sci. 166: 1497-504.

10. Kasim WA 2006. Changes Induced by Copper and cadmium stress in the anatomy and grain yield of Sorghum bicolor (L.) Moench. Iin. J. Agri. \& Bio. 1: 123-128.

11. Xie Y, Luo H, Hu L, Sun X and Lou Y 2014. Classification of genetic variation for cadmium tolerance in Bermudagrass [Cynodon dactylon (L.) Pers.] using physiological traits and molecular markers. Ecotoxicology. 1-14.

12. Hoagland DR and Arnon DI 1950. The Water-Culture Method for Growing Plants without Soil. California Agricultural Experiment Station. Circular-347.

13. Gowayed SMH and Almaghrabi OA 2013. Effect of copper and cadmium on germination and anatomical structure of leaf and root seedling in maize (Zea mays L.). Australian Journal of Basic and Applied Sciences 7(1): 548-555.

14. Ahmad SH, Reshi Z, Ahmad J and Iqbal M 2005. Morpho-anatomical responses of Trigonella foenum-graecum Linn. to induced cadmium and lead stress. J. Plant Biol. 48 (1): 64-84.

15. Mondal NK, Das C, Roy S, Datta JK and Banerje 2013. Effect of varying cadmium stress on chickpea (Cicer arietinum L) seedlings: An ultrastructural study. Annals of Environmental Science 7: 59-70

16. Sridhara BBM, Diehl SV, Han FX, Monts DL and Su Y 2005. Anatomical changes due to uptake and accumulation...... Environ. and Exp. Bot. 54(2): 131-141.

17. Shi G and Cai Q 2008. Photosynthetic and anatomic responses of peanut leaves to cadmium stress. Photosynthetica 46(4):627-630.

18. Pereira MP, Rodrigues LCA, Correa FF, Ribeiro VE and Pereira FJ 2016. Cadmium tolerance in Schinus molle trees is modulated by enhanced leaf anatomy and photosynthesis. Trees 30(3): 807-814. 